TABLE/FIG-1. Demographic and clinical variables of our cohort and their association with ON.

\begin{tabular}{|c|c|c|c|}
\hline Variables & CASES (6) & CONTROLS (12) & p-value \\
\hline $\begin{array}{l}\text { Gender: } \\
\text { Female } \\
\text { Male }\end{array}$ & \begin{tabular}{|l|}
$5(33.3 \%)$ \\
$1(33.3 \%)$ \\
\end{tabular} & $\begin{array}{l}10(66.6 \%) \\
2(66.6 \%)\end{array}$ & 1.00 \\
\hline Age $^{*}$ & $32.50 \pm 18.38$ & $33.33 \pm 11.83$ & 0.511 \\
\hline $\begin{array}{l}\text { Ethnic group: } \\
\text { Caucasian } \\
\text { Hispanic American } \\
\text { Afro-American } \\
\text { Asian } \\
\end{array}$ & $\begin{array}{l}5(35.7 \%) \\
1(33.3 \%) \\
0(0 \%) \\
0(0 \%) \\
\end{array}$ & $\begin{array}{l}9(64.2 \%) \\
2(66.6 \%) \\
0(0 \%) \\
1(100 \%) \\
\end{array}$ & 1.000 \\
\hline $\begin{array}{l}\text { Body Mass Index } \\
\text { (BMI)* }\end{array}$ & $25.72 \pm 2.38$ & $22.89 \pm 3.79$ & 0.134 \\
\hline $\begin{array}{l}\text { Smoking: } \\
\text { Yes } \\
\text { Former smoker }\end{array}$ & $\begin{array}{l}0(0 \%) \\
2(66.6 \%) \\
\end{array}$ & $\begin{array}{l}3(100 \%) \\
1(33.3 \%)\end{array}$ & 0.312 \\
\hline Dyslipidemia & $2(40 \%)$ & $3(60 \%)$ & 1.000 \\
\hline Hypertension & $5(62.5 \%)$ & $3(37.5 \%)$ & 0.043 \\
\hline Diabetes Mellitus & $2(100 \%)$ & $0(0 \%)$ & 0.098 \\
\hline Photosensitivity & $4(33.3 \%)$ & $8(66.6 \%)$ & 1.000 \\
\hline Oral ulcers & $3(60 \%)$ & $2(40 \%)$ & 0.268 \\
\hline Arthritis & $6(37.5 \%)$ & $10(62.5 \%)$ & 0.529 \\
\hline Pleuritis & $0(0 \%)$ & $1(100 \%)$ & 1.000 \\
\hline Pericarditis & $0(0 \%)$ & $2(100 \%)$ & 0.529 \\
\hline Leukopenia & $3(30 \%)$ & $7(70 \%)$ & 1.000 \\
\hline Nephritis & $2(40 \%)$ & $3(60 \%)$ & 1.000 \\
\hline Antinuclear antibody & $5(29.41 \%)$ & $12(70.59 \%)$ & 0.333 \\
\hline Anti-dsDNA & $3(25 \%)$ & $9(75 \%)$ & 0.344 \\
\hline Anti-Sm & $0(100 \%)$ & $4(100 \%)$ & 0.245 \\
\hline Anti-SSA (Ro) & $2(28.57 \%)$ & $5(71.43 \%)$ & 1.000 \\
\hline Anti-RNP & $0(0 \%)$ & $4(100 \%)$ & 0.245 \\
\hline Hypocomplementemia & $3(25 \%)$ & $9(75 \%)$ & 0.344 \\
\hline $\begin{array}{l}\text { SLICC: } \\
0 \\
1 \\
2 \\
3 \\
\end{array}$ & $\begin{array}{l}2(16.67 \%) \\
3(60 \%) \\
0(0 \%) \\
1(100 \%) \\
\end{array}$ & $\begin{array}{l}10(83.3 \%) \\
2(40 \%) \\
0(0 \%) \\
0(0 \%)\end{array}$ & 0.057 \\
\hline SLEDAI* & $2.33 \pm 2.34$ & $2.50 \pm 2.28$ & 0.883 \\
\hline APS associated & $1(50 \%)$ & $1(50 \%)$ & 1.000 \\
\hline $\begin{array}{l}\text { Corticosteroids (past } \\
\text { YES/NO) }\end{array}$ & $6(35.2 \%)$ & $11(64.7 \%)$ & 1.000 \\
\hline $\begin{array}{l}\text { Corticosteroids (last } \\
\text { visit YES/NO) }\end{array}$ & $3(100 \%)$ & $0(0 \%)$ & 0.025 \\
\hline $\begin{array}{l}\text { Corticosteroids pulses } \\
\text { (YES/NO) }\end{array}$ & $4(80 \%)$ & $1(20 \%)$ & 0.022 \\
\hline
\end{tabular}

*: mean \pm standard deviation.

\section{AB0560 A 10-YEAR REVIEW OF DAMAGE ACCRUAL AND PROGRESSION IN A MULTI-ETHNIC COHORT OF SYSTEMIC LUPUS ERYTHEMATOSUS (SLE) IN MALAYSIA}

Syahrul Sazliyana Shaharir ${ }^{1}$, Wong Michelle Heng Ting ${ }^{1}$, Asrul Abdul Wahab ${ }^{2}$, Sakthiswary Rajalingham ${ }^{1}$, Abdul Halim Abdul Gafor ${ }^{3}$, Mohd Shahrir Mohamed Said ${ }^{1}$, Ruslinda Mustafar ${ }^{3} .{ }^{1}$ Universiti Kebangsaan Malaysia, Rheumatology unit, Department of Internal Medicine, Kuala Lumpur, Malaysia; ${ }^{2}$ Universiti Kebangsaan Malaysia Medical Centre, Immunology and Microbiology Department, Kuala Lumpur, Malaysia; ${ }^{3}$ Universiti Kebangsaan Malaysia, Nephrology Unit, Department of Internal Medicine, Kuala Lumpur, Malaysia

Background: Systemic Lupus Erythematosus (SLE) is a chronic autoimmune disease with an unpredictable course of disease. The severity and outcomes of SLE vary across different ethnicities.

Objectives: This study is aimed to determine the pattern of development and progression of organ damage in a cohort of multi-ethnic SLE patients followed for at least 10 years, and to identify the factors associated with the damage accrual.

Methods: We reviewed the medical records of an inception cohort of patients who attended regular monitoring since 2007 at the Rheumatology and Nephrology/SLE Clinic, National University of Malaysia Medical Centre (UKMMC). Their medical records were retrospectively reviewed to obtain information on SLE disease characteristics, frequency of disease flares, cumulative corticosteroid dose and the use of other immunosuppressive treatment from 2007 until their last visit in 2017. The Systemic Lupus International Collaborating Clinics/American College of Rheumatology damage index (SDI) was used to determine the organ damage at baseline and after 10 years of being followed up. For patients who have succumbed or lost to follow up during the 10-year observation period, the SDI scores just before death or time of follow up loss were recorded. Results: A total of 258 patients were included with majority of them were Malays $(n=145,56.2 \%)$, followed by Chinese $(n=100,38.8 \%)$ and Indians $(n=13,5.0 \%)$. The mean SDI score increased from $0.39 \pm 0.79$ at baseline to $1.13 \pm 1.47$ after 10 years, $\mathrm{p}<0.001$. At 10 years, Indian patients were found to have a significant increase in their SDI scores from baseline compared to Malay and Chinese $(\mathrm{p}<0.05)$. New damage accrual was recorded in $38.8 \%$ patients with the most common new organ damage significantly occurred in renal $(p<0.001)$, ocular $(p=0.05)$ and cardiovascular $(p=0.07)$. Higher age at baseline, higher ACR criteria at diagnosis, persistent active disease $\geq 6$ months, and prednisolone use of $\geq 1 \mathrm{mg} / \mathrm{kg}$ were independently associated with higher risk of damage accrual. In contrast, hydroxychloroquine treatment was associated with lower risk of damage accrual.

Conclusion: The SDI scores of our SLE cohort increased significantly over 10 years which predominantly affecting the renal. Indian patients accumulated higher SDI scores while persistent active disease, higher $\mathrm{ACR}$ criteria at diagnosis, and the use of high dose steroid were associated with new organ damage.

\section{REFERENCES}

[1] Bruce IN, O'Keeffe AG, Farewell V, et al. (2015) Factors associated with damage accrual in patients with systemic lupus erythematosus: results from the Systemic Lupus International Collaborating Clinics (SLICC) Inception Cohort. Ann Rheum Dis 74(9):1706-13.

[2] Yee CS, Su L, Toescu V, et al. (2015) Birmingham SLE cohort: outcomes of a large inception cohort followed for up to 21 years. Rheumatology (Oxford) 54(5):836-43.

Acknowledgement: This study received funding from the Fundamental Research Grant Scheme (FRGS/1/2015/SKK02/UKM/03/1) from the Ministry of Higher Education, Malaysia.

Disclosure of Interests: Syahrul Sazliyana Shaharir: None declared, Wong Michelle Heng Ting: None declared, Asrul Abdul Wahab: None declared, Sakthiswary Rajalingham Speakers bureau: Pfizer. Less than 1000USD, Abdul Halim Abdul Gafor: None declared, Mohd Shahrir Mohamed Said Speakers bureau: Eli Lilly. Less than 2000USD, Ruslinda Mustafar: None declared

DOI: 10.1136/annrheumdis-2019-eular.1013

\section{\begin{tabular}{|l|l}
\hline AB0561 & RISK FACTORS FOR ADVERSE PREGNANCY \\
\hline
\end{tabular} OUTCOMES AND LOW RISK FACTORS FOR ADVERSE PREGNANCY OUTCOMES AND LOW APGAR SCORES OF NEWBORNS IN WOMEN WITH SYSTEMIC LUPUS ERYTHEMATOSUS}

Hiromi Shimada, Risa Wakiya, Mai Mahmoud Fahmy Mansour,

Shusaku Nakashima, Mikiya Kato, Taichi Miyagi, Tomohiro Kameda,

Hiroaki Dobashi. Kagawa University, Department of Internal Medicine, Division of

Hematology, Rheumatology and Respiratory Medicine, Faculty of Medicine,

Kagawa University, Kagawa, Japan

Background: Systemic lupus erythematosus (SLE) is an autoimmune disease that occurs in women of childbearing age, and has high risk for adverse pregnancy outcomes (APOs) $(1,2)$. Moreover, it is unclear whether maternal SLE influences the growth and development of children born from SLE mothers. Apgar scores at five minutes is a predictive factor of neurological development of newborns. However, there is no report about the association between maternal SLE and Apgar score of newborns.

Objectives: The aim of this study was to identify risk factors for APOs and for low Apgar scores of newborns from SLE mothers.

Methods: We investigated 50 SLE patients who were delivered from May 2006 to December 2018 in our institution. We examined retrospectively regarding APOs including spontaneous abortions, preterm births, premature rupture of membranes (PROM), light-for-date (LFD) newborns, and low Apgar scores of newborns. We analyzed the association between disease activity, laboratory findings, treatment agents, and APOs or Apgar scores. Results: As for APOs of SLE mothers, cases with preterm births showed higher SLE disease activity index (SLEDAI) during the first trimester $(P=$ 0.01) and higher titers of anti-double-stranded DNA (anti-dsDNA) antibodies at the time of conception $(P<0.01)$ compared to full-term births. In these cases, mean glucocortitcoid doses during pregnancy $(P=0.02)$ and the rate of treatment intensification $(P<0.01)$ was higher than fullterm birth. In the mothers who delivered LFD newborns, serum complement levels at conception were lower than in those with non-LFD newborns (C3: $P=0.02 ; \mathrm{CH} 50: P=0.05)$. Cases with spontaneous abortions and PROMs did not differ significantly from the cases without spontaneous abortions and PROMs. Apgar scores at one minute were correlated with SLEDAI during the third trimester $(P<0.01)$ and with the titer of anti-dsDNA antibodies at conception $(P<0.01)$. Additionally, Apgar scores at five minutes were correlated with the titer of anti-dsDNA 
antibodies $(P<0.01)$. In multivariate analysis, there were significant association between Apgar scores at five minutes and the titer of anti-dsDNA antibodies $(P<0.01$, Table 1$)$

Abstract AB0561 Table 1. Multivariate analysis of risk factor for Apgar score at 5 minutes

\begin{tabular}{|c|c|c|}
\hline Variable & Standard $\beta$ & P-value \\
\hline SLEDAI at third trimester & 0.361 & 0.05 \\
\hline $\mathrm{C} 3$ at conception & 0.068 & 0.62 \\
\hline Anti-dsDNA antibody at conception & \multirow{2}{*}{\multicolumn{2}{|c|}{$-0.964 \quad\left(R^{2}=0.589, P<0.0011^{*}\right)$}} \\
\hline & & \\
\hline Variable & Standard $\beta$ & P-value \\
\hline SLEDAI at third trimester & 0.367 & 0.06 \\
\hline C4 at conception & 0.047 & 0.74 \\
\hline Anti-dsDNA antibody at conception & \multirow{2}{*}{\multicolumn{2}{|c|}{$\begin{aligned}-0.973 & <\frac{<.01^{*}}{\left(\mathrm{R}^{2}=0.589, \mathrm{P}<0.001\right)}\end{aligned}$}} \\
\hline & & \\
\hline Variable & Standard $\beta$ & P-value \\
\hline SLEDAI at third trimester & 0.400 & $0.03^{*}$ \\
\hline CH50 at conception & 0.162 & 0.22 \\
\hline Anti-dsDNA antibody at conception & -0.969 & $<0.01^{*}$ \\
\hline
\end{tabular}

Conclusion: In SLE, immunological abnormalities at conception, high SLEDAI and glucocorticoid doses were risk factors for preterm birth and having a LFD newborn. Apgar scores at five minutes were significantly associated with the titer of anti-dsDNA antibodies. Minimizing disease activity before pregnancy may decrease risks for mothers and their newborns. In preconception counseling, it is important for rheumatologists to explain these risk factors to patients with SLE who hope to conceive. There is a need for long-term follow-up studies focusing on the neurological development of children born from SLE mothers.

\section{REFERENCES}

[1] Clowse ME, Jamison M, Myers E, James $\mathrm{AH}$. A national study of the complications of lupus in pregnancy. Am J Obstet Gynecol 2008;199:127.e1-6.

[2] Bundhun PK, Soogund MZ, Huang F. Impact of systemic lupus erythematosus on maternal and fetal outcomes following pregnancy: a meta-analysis of studies published between years 2001-2016. J Autoimmun 2017:79:17-27.

Disclosure of Interests: None declared

DOI: 10.1136/annrheumdis-2019-eular.4530

\section{AB0562 CARDIOVASCULAR RISK FACTORS AND FRAMINGHAM RISK SCORE IN PRIMARY SJÖGREN SYNDROME PATIENTS: A COMPARATIVE STUDY WITH MATCHED CONTROLS}

Joana Silva $^{1}$, Daniela Faria ${ }^{1}$, Joana Neves $^{2}$, Marcos Cerqueira $^{2}$,

Joana Rodrigues ${ }^{1}$, Soraia Azevedo ${ }^{1}$, José Tavares-Costa ${ }^{1}$, Filipa Teixeira ${ }^{1}$,

Carmo Afonso ${ }^{1}$, Daniela Peixoto ${ }^{1}$. 'Unidade Local de Saúde do Alto Minho,

Rheumatology, Ponte de Lima, Portugal; ${ }^{2}$ Hospital de Braga, Rheumatology,

Braga, Portugal

Background: The association between cardiovascular (CV) risk and chronic systemic inflammatory diseases has been an issue of debate. There is compelling evidence of increased CV morbidity in conditions such rheumatoid arthritis (RA) and systemic lupus erythematous (SLE) (1). Primary Sjögren's syndrome (pSS) is a chronic immune-mediated disease characterized by glandular and systemic manifestations, sharing clinical and immunological similarities with RA and SLE. However, in pSS patients the weight of cardiovascular disease attributed to traditional CV risk factors remains unclear.

Objectives: To determine the prevalence of traditional CV risk factors and long-term CV events based on the risk prediction tool of the Framingham risk score (FRS) in pSS patients.

Methods: The study included patients diagnosed with pSS, fulfilling both the 2016 ACR/EULAR and 2002 AECG criteria for the disease, followedup at our Rheumatology department and 49 age and sex-matched controls. Inclusion criteria were age 30 to 74 and no history of CV events in order to calculate the FRS. In total, 46 out of 54 patients were eligible for the study. Data on the prevalence of traditional CV risk factors (diabetes, arterial hypertension and smoking), systolic blood pressure (SBP) values, total and high-density lipoprotein (HDL) cholesterol levels were collected and compared between groups. The 10-year risk for CV events according to FRS was calculated and means of patients and controls were compared. Parametric and nonparametric tests were used and the level of significance was defined as $p<0.05$.

Results: The mean age of pSS patients and healthy individuals was 58.0 \pm 11.6 and $54.1 \pm 13.6$ years, respectively. The prevalence of arterial hypertension was higher in pSS patients than controls $(52.2 \%$ versus $24.5 \%$, $\mathrm{p}=0.005$ ). The prevalence of diabetes and smoking did not differ significantly between the two groups $(p=0.674$ and $p=0.949$, respectively). The SBP values, total and HDL cholesterol levels were also similar between pSS patients and healthy subjects $(p=0.063, p=0.413$ and $p=0.217$, respectively).

Mean 10-years risk for CV events assessed by FRS was $11.8 \pm 8.3$ for pSS patients and $7.8 \pm 8.4$ for matched controls, with statistically significant difference $(p=0.013)$.

Conclusion: In our study, pSS patients had a higher prevalence of arterial hypertension, which is in agreement with the $M$. Juarez et al (1) study. Although there were no significant differences in the other traditional CV risk factors, the results showed an increased 10-year risk for major CV events based on FRS assessment in pSS patients in comparison to age and sex-matched controls.

\section{REFERENCES}

[1] M. Juarez, et al. Cardiovascular Risk Factors in Women With Primary Sjogren's Syndrome: United Kingdom Primary Sjogren's Syndrome Registry Results. Arthritis Care \& Research. Vol. 66, No. 5, May 2014, pp 757-764.

Disclosure of Interests: None declared DOI: 10.1136/annrheumdis-2019-eular.7191

\section{AB0563 TRAUMA AND SLE-CONSIDERATIONS REGARDING A GROUP OF PATIENTS FROM ROMANIA}

Ana Alwina Stan, Monica Copotoiu. Tirgu-Mures Emergency Clinical County Hospital, Rheumatology, Tirgu-Mures, Romania

Background: Systemic lupus erythematosus (SLE) represents a complex disease, which hasn't got a clear etiology established yet. Many geneticsusceptibility factors, environmental triggers, antigen-antibody (Ab) responses, B-cell and T-cell interactions, and immune clearance processes interact to generate and perpetuate autoimmunity. One of the trig gers could be trauma-surgeries, serious infections or accidents.

Objectives: To assess the presence of history of trauma in patients diagnosed with SLE admitted in our Department, as well as the association with different co-morbidities.

Methods: We included 62 patients, admitted in the Rheumatology Department of the Tirgu-Mures Emergency Clinical County Hospital between 01.01.2018-29.01.2019, previously diagnosed with SLE. We performed a retrospective analysis of their medical documents, looking for evidence of traumatic risk factors.

Results: The majority of the patients were female $(17=88.70 \%)$ and had some kind of trauma before being diagnosed with SLE (17=27.41\%). Among the operations the most frequent were hysterectomy with bilateral oophorectomy and classical appendectomy, respectively (6=9.67\% each), followed by cholecystectomy and tonsillectomy $(2=3.22 \%)$. There were also one case of cerebral injury following a car accident and a complicated peritonitis-related to IUD extraction. The majority of co-morbidities was represented by neurologic involvement $(16=25.80 \%)$, followed by thyroid $(13=20.96 \%)$ and renal involvement $(12=19.35 \%)$.

Conclusion: Patients with SLE from our department have a significant history of traumatic triggers, mainly open surgeries, which might explain the development of autoimmunity. They also have various organ involvement that sometimes warrants aggressive measures. Further studies have to be conducted in order to better examine the possible link between traumatic events and development of this multifaceted disease.

\section{REFERENCES}

[1] Christie M Bartels- Systemic lupus erythematosus (SLE) on Medscape Drugs \& Diseases

Disclosure of Interests: Ana Alwina Stan Grant/research support from: Novartis, Monica Copotoiu Grant/research support from: Novartis DOI: 10.1136/annrheumdis-2019-eular.1814

\section{AB0564 THE CONTROVERSIAL ROWELL SYNDROME: TO BE OR NOT TO BE?}

Daisy AM Vaida-Voevod ${ }^{1}$, Ioana Felea ${ }^{1}$, Laura Damian ${ }^{1}$, Cristina Pamfil ${ }^{2}$, Simona Rednic ${ }^{1,2}$. ${ }^{1}$ Emergency County Hospital Cluj, Rheumatology, Cluj-Napoca, Romania; ${ }^{2}$ University of Medicine and Pharmacy luliu Hatieganu, Rheumatology, Cluj-Napoca, Romania

Background: Rowell syndrome is a rather rare and highly debated entity, initially defined by Rowell et all as discoid lupus associated with 